Surprisingly, perhaps, few exhibits in this section dealt in detail with the administration of large collections. All the more interesting therefore were the exhibits of the curation of extensive insect and mammal collections, which demonstrated the importance to taxonomic research of type specimens, named series, and the most effective physical arrangements of animals of widely varying shapes and sizes. The proper curation of large collections requires speedy and accurate storage and retrieval, not only of objects but also of information about the objects. This presents a problem that is further complicated by the difficulty of deciding how much information the objects themselves display and how much should be documented. As exhibits in the sections of the demonstration on analysis and synthesis and presentation and dissemination revealed, this complication is becoming increasingly troublesomo. Small collections made for special research purposes appear to be readily suitable for documentation with punched cards, special maps and other recent innovations.

The exhibits displayed in the section dealing with examination and extraction of information were all concerned with methods of obtaining information not immediately detectable without the help of instrumentation, and this section, porhaps more than any other in the demonstration, showed how very many developments in the physical sciences are rapidly turned to their advantage by taxonomists. 'Two oxhibits of striking electronmicrographs complemented nicely a demonstration of the range of light microscope techniques. X-ray illustrations of skeletal structures, moulds of leaf surfaces, and electronic recordings of insect sounds were the themes of other exhibits showing exploitation of techniques which might be thought to belong solely within the fields of the physical sciences.

Demonstrations of the uses to taxonomists of paper chromatography, electrophorotic separation of proteins, and a varioty of serological techniques indicated th $\theta$ increasing significance to taxonomy-especially of $\gamma$ taxonomy - of advances in biochemistry.

Many techniques and instruments can provide the taxonomist with assessable information, and a point which the exhibits in this section underlined is that no one technique, whether simple or the ultimate in sophistication, can be held to be the most useful. It was perhaps unfortunate that there was no exhibit which domonstrated the usefulness in taxonomy of the unaided human senses and such simple instruments as callipers.

Just as the significance to taxonomy of the human senses is not easy to display, so the vital importanco of human mental processes of induction and deduction did not lond thomselves readily to demonstration in the section on analysis and synthesis. The ever-increasing use of mathematical and geometrical methods of analysis and synthesis in taxonomy was demonstrated by the use of geometrical transformations of structure and a wide array of methods of multivariate analysis. The development of these last techniques, which is closely linked with advances in computer technology, allows taxonomists to take on research problems which, in the past, would have required many years for completion-if indeed they could have beon contemplated - but which can nowadays be completed in a few weeks or months. Numerical treatment of taxonomic data is still a subject of much controversy; but there can be no doubt that its use encourages taxonomists to regard the organisms with which they deal as parts of populations. This is essential for progress in some areas of taxonomy; but what is urgently needed, if numerical taxonomy is to become an accopted tool of routine identification and classification, is proof that the labour of collecting the vast quantities of data required for the statistics is rewarded by greatly increased usofulnoss of the results.

Numerical methods of analysis and synthesis may allow taxonomists to handle rapidly large amounts of data; but, as the section concerned with presentation and dissemination of results showed all too clearly, biological data are not the only items which are accumulating faster than they can be handlod by traditional methods. Collections of organisms are growing rapidly all the time, and will continue to grow at a high rate for many years to come. Every specimen is a source of useful information, and so, ideally, every specimen should be easily retrieved from the collection, while the information which accompanies it should be readily available. Unfortunately, because of the continued growth of collections, and because the theories and practice of information storage and retrieval are still in an carly stage of development, probably all institutions which maintain large collections are faced with apparently insuperable problems of management. While collections the items of which can be counted in hundreds can be adequately controlled and used by means of written guides and indices, theso time-honoured methods cannot be efficient where collections must be numbered in tens or hundreds of thousands. Considerable thought is now going into the design of machinery and procedures which can deal efficiently and rapidly with the documentation and control of large collections. If these efforts are successful the exchange of information and material between taxonomists could be greatly improved.

Not only are collections of organisms expanding at a tremendous rate but the volume of published work which each taxonomist must review grows every year. Collection management and the control of published results have many problems in common, and many of the same principles are employed to devise information storago and retrieval aids in both ficlds. However, some problems of bibliography control can be solved more easily than can their counterparts in collection management. Uniform high standards of illustration, typography and layout can be demanded, as can condensation of text, but organisms to be stored will always be highly heterogeneous in the amount of information which they reveal on casual inspection and in their storage requirements. It was clear from several exhibits in this section that much taxonomic publication could be standardized to allow efficient storage and easy perusal. Ideas differ as to the best ways of achieving these aims, and it is to be hoped. that some measure of agreoment will be reached soon. Otherwise the taxonomist will find himself forced to read yet more journals with different and conflicting methods of prosentation.
WiLimam G. Fry

\title{
TELEVISION AND RADIO IN BRITAIN
}

$I^{\mathrm{N}}$ $\mathrm{N}$ opening a debato on broadcasting in the House of Commons on May 13, Sir Peter Rawlinson pressed for information as to the Government's plans for television and advocated that the new fourth channel should bo devotod to commercial television. As regards sound broadcasting, he thought that this was the appropriate time to encourage local broadcasting and the right solution was to be found in Iow-range local broadeasting stations. In replying for the Government, the PostmasterGeneral, Mr. Wedgwood Benn, said that it was essential bofore taking a decision on tho allocation of the fourth channel that we should be clear as to what purposes the fourth channel should be required to meet. Educational broadeasting was very closoly tied to the question of the 
fourth channel and this was being urgently considered, as well as the alternative possibilities, including the utiliza. tion of unused hours; decision would only be reached after most careful consideration of the alternatives.

On colour television, he said that the failure of the Vienna Conference to reach agreement on an acceptable uniform colour system in Europe had set back our hopes of European standardization. For Great Britain, the choice, if one had to be made, lay between American and European systems and would be a particularly difficult one, which would be even harder if there were two different systems on the Continent of Europe and not just one. We would also have to consider the question of payment for colour television, and it might not be right to ask the main body of licence holders to pay for a colour service which they may never wish or be able to afford to receive themselves.

Pirate ships had no part whatever in the future development of broadcasting in Britain or in Europe. They were interfering with reception in other countries, and the development of a really serious pattern of local sound stations in Britain depended on the use of very high frequency which made a great number of channels available.

Mr. Benn restated the traditional doctrine which had been accepted by all governments and was designed. as a safeguard against political interference. There was a great danger in going beyond this limit with regard to ministerial interference. Mr. Benn insisted that the increase of the licence fee was fully justified and would only hold the present position and keep the British Broadcasting Corporation within its present borrowing limits. We had reached a point where the Corporation could no longer rely in anything like the previous extent on increased revenue arising from new licence holders. The Government was satisfied that all reasonable economy was exercised within the Corporation, and the review in which the Corporation was co-operating was instituted in view of the changed position for increased revenue.

The problem of evasion was also being examined. In reaching its decisions, Mr. Benn said the Government would be guided by its profound belief in the growing importance of radio and television to the community and to the world, by its desire to see television and radio expand as rapidly as national resources permitted, to meet important national needs and to develop still further their potential for education, information and entertainment. It also recognized that technological changes had opened up new possibilities which had hitherto been entirely excluded. It was determined to uphold and entrench the principle of public service in all further development in television and radio, and it also wished to allow the greatest possible freedom and scope for creative talents to express themselves through radio and television. It was prepared to consider fully the various methods by which broadcasting could be financed, including a combination of broadcasting licences, grantsin-aid, local government grants and advertising revenue under proper supervision.

Mr. W. Shepherd, who followed, agreed that a decision on the fourth channel should not be rushed, but he did not wish to see existing contractors given any more scope, or contractors obtained who had made fortunes elsewhere. $\mathrm{He}$ and subsequent speakers were somewhat critical of standards maintained by the British Broadcasting Corporation, and in the debate there was strong support for the development of local broadcasting. Mr. $H$. Bowden, replying for the Government, added little to what Mr. Benn had said, but reiterated the need for increased educational facilities and the dependence of a decision on the fourth channel on a careful review of the whole situation.

\title{
EXPERIMENTAL EVIDENCE OF A TWINKLING LAYER IN THE EARTH'S ATMOSPHERE
}

\author{
By CRAIG C. HUDSON \\ Sandia Corporation, Sandia Base, Albuquerque, New Mexico
}

\begin{abstract}
$\mathrm{T}$ $\mathrm{HE}$ scintillation of stars is that part of astronomical seeing which deals with intensity fluctuations of the image, more commonly called twinkling. A large part of twinkling occurs at frequencies too high to be observable to the human eye, that is, greater than $15 \mathrm{c} / \mathrm{s}$. For many years the cause has been thought to reside in the atmosphere, in the form of fluctuations in the index of refraction caused by air turbulence.

Other optical effects, such as blurring and dancing of the image, often accompany twinkling, but can be distinguished from it both by the method of observation and by layer of origin in the atmosphere.

Reviews of the various experiments and theories of astronomical seeing (especially twinkling) are included in Tatarski's well-known monograph ${ }^{1}$, in the report by Keller et al. ${ }^{2}$, and in the report by Wimbush ${ }^{3}$. The present discussion will be limited to twinkling.

The observational properties of star twinkling have beon reported by many ${ }^{4-7}$. It is least in the zenith direction and has the broadest frequency spectrum there. For low angles of observation, the amplitude increases but the high frequency end of the spectrum fades away. The spectrum near zenith is approximately flat below 100 $\mathrm{c} / \mathrm{s}$ but falls off rapidly at higher frequencies. Twinkling is enhanced by the use of a small aperture, and tends to a minimum for apertures greater than $20 \mathrm{in}$. diameter. For small apertures, the modulation (fluctuation relative to mean light level) can exceed 100 per cent even at the
\end{abstract}

zenith, while for large apertures $10-20$ per cent is more typical. Twinkling also depends on the source size; the larger planets, for example, showing very little effect. Finally, twinkling depends on meteorological conditions; in particular, there is correlation between the intensity of the effect and the speed of winds above $20,000 \mathrm{ft}$.

Contemporary theories of twinkling, according to Keller ${ }^{2}$, can be classified into three groups: $(a)$ those governed by the refraction of light by turbulent elements of large size not too far from the observer (also contributing to blurring and dancing); (b) those governed by the diffraction of light with the zeroth order predominating (thin layer); and (c) those governed by the diffraction of light with the higher orders predominating (thick layer). Using a theory of type (a), Chandrasekhar ${ }^{8}$ deduced that twinkling could be explained on the basis of a hypothetical layer $100 \mathrm{~m}$ thick, of homogeneous, isotropic turbulence at $4 \mathrm{~km}$ altitude. Keller suggests a thinner layer at a higher altitude. Wimbush argues against a discrete layer, citing evidence of several other workers in favour of a continuous distribution of turbulence.

Keller ${ }^{2}$, using Protheroe's autocorrelation data ${ }^{9}$, made a parameter study on the basis of the theory of scintillation $^{10,11}$ which is of interest in what follows. The scale of turbulence is $L_{m} ; \Delta z$ is the layer thickness; and $\delta^{2} n$ is the mean square fluctuation of the index of refraction. By assuming no pressure fluctuations, $\delta^{2} n$ may be transformed into the mean square temperature fluctuation $\delta^{2} T$. Estim- 